Eixo Temático: Biologia Aplicada

\title{
ET-09-015 \\ PERCEPÇÃO DOS ALUNOS DO 9' ANO DE UMA ESCOLA PÚBLICA DE RECIFE, PERNAMBUCO, SOBRE A IMPORTÂNCIA DOS PEQUENOS MAMÍFEROS COMO DISPERSORES DE SEMENTES NA FLORESTA ATLÂNTICA
}

Tatiane França Melo${ }^{1}$; Anna Claudia Aca Ferreira ${ }^{1}$; Danúbia Guimarães Silva ${ }^{1}$; Martin Alejandro Montes²; Ana Cristina Lauer Garcia ${ }^{1}$

1Programa de Pós-Graduação em Saúde Humana e Meio Ambiente. Centro Acadêmico de Vitória, Universidade Federal de Pernambuco - UFPE. Rua do Alto do Reservatório s/n. Vitória de Santo Antão-PE. (CEP 55608-680).

${ }^{2}$ Laboratório de Genética, Bioquímica e Sequenciamento de DNA. Universidade Federal de Pernambuco - UFRPE. Rua Dom Manoel de Medeiros, s/n. Recife-PE (CEP 52171-900).

http://dx.doi.org/10.21472/congrebio2016.et-09-015

\section{RESUMO}

As florestas úmidas são consideradas um dos ambientes mais ricos em espécies, incluise a Floresta Atlântica que apresenta grande parte das espécies do mundo e um vasto número de endemismos. Um grupo que pode colaborar na conservação de florestas são os pequenos mamíferos, os quais influenciam na regeneração de plantas através da dispersão de sementes. Também como importante contribuinte neste processo, temos a percepção ambiental que alia o conhecimento popular ao meio ambiente com o intuito de minimizar os problemas ambientais. O objetivo do presente estudo foi avaliar a percepção dos estudantes do nono ano de uma escola pública sobre a importância dos pequenos mamíferos na dispersão de sementes na Floresta Atlântica. A pesquisa foi realizada em dezembro de 2015 com alunos do nono ano do Ensino Fundamental de escola pública, em um bairro da cidade do Recife próximo de uma área de Floresta Atlântica. Para este público foi apresentada uma palestra na sala de aula sobre a importância dos pequenos mamíferos dispersores de sementes na Floresta Atlântica. Após a apresentação foi aplicado um questionário aos alunos. Os dados foram analisados por meio de estatística descritiva e representados os percentuais. Mais da metade dos estudantes responderam que desconheciam a Floresta Atlântica. Em relação à importância dos roedores e marsupiais, a maioria respondeu que esses animais são importantes na dispersão de sementes, contribuindo para a manutenção do ecossistema. Sobre a fauna deste bioma, os alunos tiveram pouco conhecimento, sendo os animais mais citados o rato doméstico e o timbu. Referente à importância da preservação da Floresta Atlântica do Parque Estadual de Dois Irmãos, 45,5\% relacionaram o processo de fotossíntese com a manutenção da vida de todas as espécies. Os estudantes não demonstraram ter domínio de informações básicas em relação às funções do ecossistema florestal, porém demonstraram conhecimento sobre a função ecológica dos dispersores de sementes. Esta pesquisa foi relevante para avaliar o conhecimento dos estudantes e para o estabelecimento de futuras práticas que possam gerar bons frutos a favor da natureza. (Cnpq/CAPES).

Palavras-chave: Frugivoria, Parque Dois Irmãos, Roedores e marsupiais.

\section{INTRODUÇÃO}

As florestas úmidas são consideradas mundialmente um dos locais mais ricos em espécies, sendo a Floresta Atlântica um destes ambientes. Esta floresta abriga elevada biodiversidade e grande número de endemismos. A Floresta Atlântica é considerada um dos 
cinco ambientes mais ameaçados do planeta, sua destruição iniciou com a colonização e com a exploração madeireira no Brasil. Atualmente este bioma ainda sofre com intensa pressão antrópica, pelo o fato de que a maior parte da população humana está localizada nas regiões onde havia sua cobertura original. No século XVI a Floresta Atlântica possuía uma extensão de aproximadamente $1.320 .000 \mathrm{~km}^{2}$ e atualmente está reduzida em $88 \%$ do tamanho inicial (RIBEIRO et al., 2009).

Em contrapartida há processos ecológicos importantes que contribuem para a manutenção das florestas, entre os quais podemos citar a dispersão de sementes por animais (MARTINS, 2005). Cerca de 60 a 90\% dos propágulos das espécies de vegetais são adaptados ao transporte por organismos como, por exemplo, as aves e os mamíferos (MORELLATO et al., 2000). Os pequenos mamíferos compõem um grupo que tem uma função importante neste aspecto, pois influenciam na regeneração da floresta, desempenhando o papel de disseminar sementes (PIMENTEL e TABARELLI, 2004).

Com a finalidade de buscar um equilíbrio entre o meio ambiente e as comunidades humanas, o desenvolvimento sustentável é uma forma de contribuição ambiental que pode minimizar sérios problemas como, por exemplo, o desmatamento da Floresta Atlântica. Esta prática tem como ideia um modelo que atende as necessidades das gerações atuais, pensando em alternativas de consumo consciente do meio ambiente conservando-o para as gerações futuras (VICIOSO, 1992).

Dentro deste contexto, a educação e a percepção ambiental surgem como ferramentas importantes para a proteção de áreas nativas e auxiliam na reaproximação do homem com a natureza, uma vez que despertam responsabilidade e respeito dos indivíduos em relação ao ambiente em que vivem. A percepção ambiental é a forma como estabelecemos a conscientização dos problemas relacionados ao meio ambiente, percebendo a nossa inclusão no mesmo a fim de preservá-lo (VILLAR et al., 2008).

De acordo com o exposto, o objetivo do presente estudo foi avaliar a percepção dos estudantes do nono ano de uma escola pública de Recife, Pernambuco, sobre a importância dos pequenos mamíferos para a dispersão de sementes na Floresta Atlântica.

\section{METODOLOGIA}

A pesquisa foi realizada em dezembro de 2015 com os alunos do nono ano do Ensino Fundamental da Escola Estadual José Vicente Barbosa, na cidade do Recife, Pernambuco. Utilizamos como modelo de uma floresta, o Parque Estadual de Dois Irmãos, uma unidade de

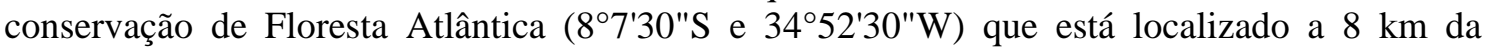
escola. A palestra sobre a importância dos pequenos mamíferos dispersores de sementes na Floresta Atlântica foi ministrada dentro de uma sala de aula por meio de uma apresentação expositiva com auxílio do DataShow. Também foram apresentadas amostras biológicas como, por exemplo, alguns animais da coleção zoológica do Laboratório de Ecologia de Mamíferos UFRPE fixados no álcool 70\%, vídeos e imagens de livre acesso disponíveis na internet, referentes aos pequenos mamíferos da Floresta Atlântica, como, por exemplo, marmosa (Marmosa murina), timbu (Didelphis albventris), punaré (Thrichomys sp.) e ratazana (Rattus norvegicus). Foram abordados três temas na palestra, a Floresta Atlântica, os dispersores de sementes e a preservação dos mesmos, para cada tema foi destinado um tempo de 45 minutos. Durante a exposição tratamos o que é floresta, a importância das florestas e da Floresta Atlântica do estado de Pernambuco, usando como modelo de floresta o Parque Estadual de Dois Irmãos. Também mencionamos a importância de conservar a natureza, inclusive como é importante preservar a floresta e os animais que nela habitam, salientando neste contexto as funções desempenhadas pelos pequenos mamíferos. Para preparação da palestra foram consultados os trabalhos de Tabarelli (2004), Martins (2005), Ribeiro (2009) e o Plano de Manejo de Parque Estadual de Dois Irmãos (2014). Após a apresentação do assunto foi aplicado um questionário impresso com seis perguntas para os alunos. A professora responsável pela disciplina de Ciências não participou da apresentação, porém interviu na aplicação dos 
questionários. As perguntas do questionário foram elaboradas com base em três temáticas: Floresta Atlântica, pequenos mamíferos como dispersores de sementes e a importância de conservação destes organismos. Para o primeiro tópico foram questionados: "Qual floresta você conhece?”, "Você conhece a Floresta de Dois Irmãos?”. Para o segundo tópico perguntamos: “O que é um animal dispersor?”, “Qual a importância dos pequenos mamíferos?”, “Cite o nome dos pequenos mamíferos que você conhece”. Finalmente questionamos: "Em sua opinião, qual a importância de preservar a Floresta de Dois Irmãos?” Todas as respostas a estas perguntas foram redigidas a mão pelos alunos com um tempo estimado de 15 minutos para as respostas. Os dados foram analisados por meio de estatística descritiva e representados os percentuais.

\section{RESULTADOS E DISCUSSÃO}

Vinte e dois alunos responderam o questionário, sendo a metade de cada sexo. Dentre os homens nove alunos apresentaram faixa etária de 15 anos, um quatorze e um treze anos. Dentre as mulheres sete estão na faixa etária de 15 anos, três tem 14 e uma com 13 anos.

Quando os alunos foram questionados sobre qual Floresta conheciam, mais da metade citou a Floresta Amazônica. Apenas 41\% dos alunos mencionaram a Floresta Atlântica, mesmo tendo aulas em uma escola muito próxima a um importante fragmento florestal deste bioma em Recife, Pernambuco. É notável como a Floresta Atlântica, mesmo sendo palco de elevada riqueza de espécies e abrangendo uma longa faixa latitudinal do Brasil (Ribeiro et al., 2009), passe despercebida por muitos alunos que vivem próximo do seu entorno.

Com relação ao conhecimento sobre a Floresta de Dois Irmãos, 31,8\% dos estudantes responderam que a conheciam. Este número é, no entanto muito baixo já que esta região é considerada uma área prioritária para a conservação da biodiversidade em Pernambuco. O Plano de manejo de Parque Estadual de Dois Irmãos (2014) salienta ser esta uma área de extrema importância biológica, compreendendo uma extensão de 1.157,72 hectares, onde se encontram pelo menos 251 espécies de borboletas, 61 espécies da herpetofauna, 199 espécies de aves e 27 espécies de mamíferos, tendo a ordem Rodentia como um dos grupos com maior quantidade de registros e em seguida a ordem Didelphimorphia.

Em relação à pergunta sobre o que é um animal dispersor a maioria dos alunos, $(72,8 \%)$, respondeu que "são animais que dispersam sementes para outros locais", 13,6\% citaram nomes dos pequenos mamíferos dispersores, 9,1\% disseram que não sabiam e 4,5\% responderam erroneamente. Deste modo, a maioria dos entrevistados demonstrou conhecer a importância dos pequenos mamíferos e a contribuição destes organismos para a dispersão dos frutos e sementes como peça fundamental na manutenção da biodiversidade (MARTINS, 2005).

Em relação à percepção dos alunos sobre a importância dos roedores e marsupiais, $45,5 \%$ estudantes responderam que esses animais são importantes na dispersão de sementes, contribuindo para manutenção do ecossistema, 31,8\% dos alunos informaram que estes organismos contribuem para o reflorestamento da floresta e cinco alunos não souberam responder, provavelmente por não terem compreendido a palestra. Percebemos que mesmo depois da apresentação da palestra 22,7\% dos estudantes, informaram que não sabiam da importância ecológica desses animais. Apesar de o Brasil ser detentor de uma grande diversidade de roedores e marsupiais (PIMENTEL e TABARELLI, 2004), o conhecimento sobre o papel destes animais na cadeia trófica, na ciclagem de nutrientes, na dispersão de sementes e na polinização, ainda não se encontra plenamente conhecida pelos entrevistados, o que certamente dificulta a compreensão da necessidade de sua preservação.

Em relação ao conhecimento de fauna de pequenos mamíferos da Floresta Atlântica, observou-se que o rato e o timbu foram os animais mais citados pelos alunos (Tabela 4). Conforme Ribeiro et al (2010) a espécie de roedor Guerlinguetus ingrami é um dispersor de sementes fundamental na Floresta Atlântica. Pimentel e Tabarelli (2004) estudaram a disseminação de sementes com o esquilo (Sciurus aestuans), gambá (Didelphis albiventris), cutia (Dasyprocta prymnolopha), paca (Agouti paca), rato-porco (Oryzomys capito) e rato catita (Monodelphis americana) e destacaram que os esquilos são mais eficientes. Além disso, os 
mamíferos de Floresta Atlântica são responsáveis por $80 \%$ da dispersão de plantas (MORELLATO, 2000).

Tabela 4. Pequenos mamíferos citados pelos alunos do nono ano do Ensino Fundamental da Escola Professor José Vicente Barbosa em Recife, Pernambuco.

\begin{tabular}{lll}
\hline Pequenos Mamíferos & Nome popular & $\mathbf{N}^{\mathbf{0}}$ de citações \\
\hline & Rato & 12 \\
& Preá & 3 \\
& Capivara & 5 \\
\multirow{2}{*}{ Roedores } & Castor & 1 \\
& Marmota & 2 \\
& Catita & 1 \\
& Ratazana & 1 \\
Marsupiais & Esquilo & 1 \\
& Timbu ou Gambá & 11 \\
\multirow{3}{*}{ Outros } & Canguru & 4 \\
& Coelhos & 1 \\
Total & Muitos & 1 \\
\hline & Não sei & 1 \\
\hline
\end{tabular}

Observamos que os alunos compreenderam a importância da preservação da Floresta do Parque Estadual de Dois Irmãos. Dos 22 estudantes, 10 relacionaram o processo de fotossíntese com a manutenção da vida de todas as espécies, enquanto nove relataram que preservar a floresta do Parque Estadual de Dois Irmãos é importante para a conservação da fauna e flora local e três alunos não souberam responder. Segundo Gross et al. (2005) este bioma fornece uma série de serviços ambientais responsáveis pela manutenção da vida na Terra, pela interação entre os seres vivos e pela oferta dos serviços que apoiam as sociedades humanas e suas economias. Esses serviços incluem alimentos, medicamentos, água, ar limpo, banco genético e outros recursos naturais que asseguram uma ampla variedade de atividades humanas.

\section{CONCLUSÕES}

Sobre as florestas os alunos demostraram ter domínio sobre a função ecossistêmica, porém apresentam deficiência no conhecimento das florestas locais. Os estudaram mostraram conhecimentos sobre a função ecológica dos dispersores de sementes e sobre quem realiza esse trabalho nas florestas próximas de suas residências. Observamos que os alunos concordam sobre a importância da preservação das florestas e dos animais que nela se encontram.

\section{AGRADECIMENTOS}

Agradecemos a Professora de Ciências Julieta, a Direção, a todos os funcionários da Escola e aos alunos que contribuíram para a realização desta pesquisa.

\section{REFERÊNCIAS}

GROSS, T.; JOHNSTON, S.; BARBER, C. V. A. Convenção sobre Diversidade Biológica: entendendo e influenciando o processo. Um Guia para entender e participar efetivamente da Oitava Reunião da Conferência das Partes da Convenção sobre Diversidade Biológica. Curitiba, 2005. 
MARTINS, R. Florística, estrutura fitossociológica e interações interespecíficas de um remanescente de Floresta Ombrófila Densa como subsídio para recuperação de áreas degradadas pela mineração de carvão, Siderópolis, SC. 2005. 94 f. Dissertação (Mestrado em Biologia Vegetal)- Universidade Federal de Santa Catarina, Florianópolis, 2005.

MORELLATO, L. P. C.; TALORA, D. C.; TAKAHASI, A.; BENCKE, C. C.; ROMERA, E. C.; ZIPPARRO, V. B. Phenology of Atlantic rain forest trees: a comparative study. Biotropica, v. 32, n. 4b, p. 811-823, 2000.

PIMENTEL, D. S., TABARELLI, M. Seed dispersal of the palm Attalea oleifera in a remnant of the Brazilian Atlantic Forest. Biotropica, v. 36, p.74-84, 2004.

RIBEIRO, L.F.; CONDE, L. O. M.; TABARELLI, M. Predação e remoção de sementes de cinco espécies de palmeiras por Guerlinguetus ingrami (Thomas, 1901) em um fragmento urbano de Floresta Atlântica Montana. Revista Árvore, v. 34, n. 4, p. 637-649, 2010. http://dx.doi.org/10.1590/S0100-67622010000400008

RIBEIRO, M. C.; METZGER J. P.; HIROTA, M. M. The Brazilian Atlantic Forest: How much is left, and how is the remaining forest distributed? Implications for conservation. Biological Conservation, v. 142, p. 1141-1153, 2009.

VICIOSO, J. R. J. Orientaciones didácticas para la Educacíon Ambiental en E. Primária. Sevilla: Junta de Andalucía, $1992 . \quad$ Disponível em: $<$ http://www.juntadeandalucia.es/medioambiente/web/Bloques_Tematicos/Educacion_Y_Partic ipacion_Ambiental/Educacion_Ambiental/Educam/Educam_I/ODEA_ed_infantil/odea_infantil _00.pdf>. Acesso em: 23 mar. 2016.

VILLAR, L. M.; ALMEIDA, A. J.; LIMA, M. C. A.; ALMEIDA, J. L. V.; SOUZA, L. F. B.; PAULA, V. S. A percepção entre os habitantes da região noroeste do estado do Rio de Janeiro. Rev. Enferm., $\quad$ v. 12, $\quad$ n. 2, $\quad$ p. 285-290, $2008 . \quad$ Disponível em: $<$ http://www.eean.ufrj.br/revista_enf/20082/15ARTIGO11.pdf>. Acesso em: 23 mar. 2016. 